\title{
Congenital adrenal hyperplasia in a male neonate presenting as unresponsive sepsis
}

\author{
Balaji MD¹, Madhava Kamath K², B. Aditya Kumar ${ }^{3}$ \\ ${ }^{1}$ Dr Balaji M D, Professor, ${ }^{2}$ Dr Madhava Kamath K, Associate Professor, ${ }^{3}$ Dr B. Aditya Kumar, Postgraduate, all authors \\ are affiliated with Department of Pediatrics, Adichunchanagiri Institute of Medical Sciences, B G Nagara, Nagamangala \\ Taluk, Mandya District, Karnataka, India.
}

Address for Correspondence: Dr B Aditya Kumar, Email: bandariaditya59@gmail.com

\begin{abstract}
Congenital Adrenal Hyperplasia (CAH) is a disease of Adrenal steroid synthesis. Classic congenital adrenal hyperplasia (CAH) due to 21 hydroxylase deficiency results in one of two clinical syndromes: a salt-losing form or a simple virilizing form. Girls with both forms present with ambiguous genitalia. Newborn males show no overt signs of CAH and so a high index of suspicion is needed to diagnose in them. We report a case of 20 day old male newborn who presented to us in shock which was resistant to routine resuscitative measures. $\mathrm{CAH}$ was suspected and was diagnosed based on $17 \mathrm{OH}$ progesterone levels.
\end{abstract}

Keywords: Congenital Adrenal hyperplasia (CAH), 17-hydroxyprogesterone, Cortisol, Androstenedione and Dehydroepiandrosterone (DHEA)

\section{Introduction}

Defective conversion of 17-hydroxyprogesterone to 11deoxycortisol account for more than 90 percent of cases of congenital adrenal hyperplasia (CAH) [1]. This conversion is mediated by 21-hydroxylase, the enzyme encoded by the $C Y P 21 A 2$ gene. It results in decreased cortisol synthesis and therefore increased adrenocorticotropic hormone (ACTH) secretion. The resulting adrenal stimulation leads to increased production of androgens [2].

Patients with "classic" or the most severe form of $\mathrm{CAH}$ due to 21-hydroxylase deficiency present during the neonatal period and early infancy with adrenal insufficiency with or without salt-losing, or as toddlers with virilization. Females have genital ambiguity [1].

"Nonclassic," or late-onset 21-hydroxylase deficiency, presents later in life with signs of androgen excess and without neonatal genital ambiguity. Clinical features in childhood may include premature pubarche, and accelerated bone age; adolescent and adult females may present with hirsutism, menstrual irregularity, infertility, and acne. Some patients with nonclassic $\mathrm{CAH}$ remain asymptomatic [2].

\section{Case Report}

A 20 day old male baby presented to us in shock. Mother gave history of reduced activity and decreased urine output from the past two days. On examination baby was found emaciated and dehydrated. Baby was stabilized with boluses of normal saline and inotropes and was ventilated. Relevant blood investigations were sent. Baby was found to have Hypoglycemia, Electrolyte abnormalities - Hyponatremia, Hyperkalemia and increased Blood urea and creatinine. An intravenous bolus of 2 to $4 \mathrm{~mL} / \mathrm{kg}$ of 10 percent dextrose was given in view of significant hypoglycemia. Hyperkalemia was corrected with the administration of glucose and insulin. Initially we suspected Late Onset Sepsis with Acute Renal Failure and started treatment on those lines. Broad spectrum antibiotics like Vancomycin, Meropenem were started and their dose was adjusted based on the creatinine clearance. But still child continued having episodes of Hypoglycemia even with Glucose Infusion Rate (GIR) $12 \mathrm{ug} / \mathrm{kg} / \mathrm{min}$ resulting in seizures and persistent electrolyte abnormalities.

Manuscript received: $18^{\text {th }}$ January 2017

Reviewed: $25^{\text {th }}$ January 2017

Author Corrected: $2^{\text {nd }}$ February 2017

Accepted for Publication: $9^{\text {th }}$ February 2017 
At this point of time we suspected Congenital Adrenal Hyperplasia and 17-OH progesterone levels were sent and child was started on glucocorticoid and mineralocorticoid supplementation. We were able to wean off the baby from ventilator and taper the GIR to $4-6 \mathrm{ug} / \mathrm{kg} / \mathrm{min}$ within two days of starting steroid supplementation. The childs $17-\mathrm{OH}$ progesterone level was $3700 \mathrm{ng} / \mathrm{ml}$ which was remarkably elevated and so supplementation of steroids was continued. Gradually baby was put on Direct Breast Feeding and was shifted to mother side. Baby gained $1 \mathrm{~kg}$ weight by the time of discharge.

\section{Discussion}

A very high serum concentration of 17-hydroxyprogesterone, the normal substrate for 21-hydroxylase, is diagnostic of classic 21-hydroxylase deficiency. Most affected neonates have concentrations greater than $3500 \mathrm{ng} / \mathrm{dL}(105 \mathrm{nmol} / \mathrm{L})[3]$.

To define the exact metabolic defect in infants, serum concentrations of 11-deoxycortisol, 17-hydroxypregnenolone, cortisol, androstenedione, and dehydroepiandrosterone (DHEA) should also be measured, listed in order of priority [2].

\section{Synthetic defect in CYP21A2 (21-hydroxylase) deficiency}

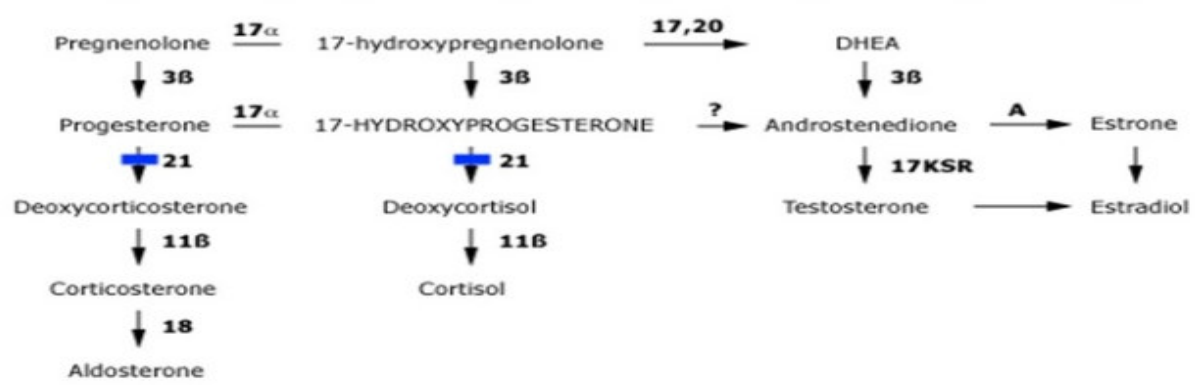

Pathways of adrenal steroid synthesis. A synthetic defect in 21-hydroxylase leads to diminished cortisol synthesis, increased release of corticotropin (ACTH), accumulation of 17-hydroxyprogesterone (particularly after the administration of ACTH), possible virilization due to increased androgen production, and possible salt-wasting due to diminished production of aldosterone and deoxycorticosterone.

The numbers at the arrows refer to specific enzymes: 17a: 17a-hydroxylase (P450c17); 17,20: 17,20 lyase which is part of the P450c17 enzyme; $3 \beta$ : $3 \beta$-hydroxysteroid dehydrogenase; 21: 21-hydroxylase (P450c21); 11B: 11B-hydroxylase; (P450c11); 18 refers to the two-step process of aldosterone synthase (P450c11as), resulting in the addition of an hydroxyl group that is then oxidized to an aldehyde group at the 18-carbon position; ?: unclear if pathway functions in vivo; DHEA: dehydroepiandrostenedione; 17KSR: 17-ketosteroid reductase; and A: aromatase.

\section{Figure-1: Picture depicting Adrenal steroid synthesis and enzymes involved}

Adrenal ultrasonography is another potential adjunctive test for congenital adrenal hyperplasia in neonates when the diagnosis is equivocal based upon other testing [4].

In many countries, including the United States, neonatal screening for 21-hydroxylase deficiency is an approved part of the neonatal screening program. The screening test for 17a-hydroxyprogesterone (17OHP) is measured using a filter paper blood sample obtained by a heel puncture preferably between two and four days after birth. The assay used in most programs is a fluoroimmunoassay [5].

The goals of classic $\mathrm{CAH}$ newborn screening are early detection of the severe, salt-wasting form, therefore prevention of adrenal crisis or death, early detection of the simple virilizing form, and prevention or shortening of the period of incorrect gender assignment in females. The screening was not introduced to detect newborns with the non-classic form of CAH. To further improve CAH neonatal screening, new strategies have been developed and introduced in the NBS such as a second-tier CAH assay in which the fluoroimmunoassay was followed by Tandem mass spectrometry which offers a high level of analytical sensitivity [6]. Genetic testing, which detects approximately 90 to 95 percent of mutant alleles, can also be used to evaluate borderline cases. Genetic testing should only be done if the adrenocortical testing is equivocal or for purposes of genetic counselling [7]. 
Prenatal diagnosis should be considered when a foetus is known to be at risk because of an affected sibling, or when both partners are known to be heterozygous for one of the severe mutations, thus predicting a one in eight chance of female genital ambiguity. Measurements of amniotic fluid 17-hydroxyprogesterone, human leukocyte antigen (HLA) typing of fetal cells, and molecular analysis of fetal CYP21A2 genes in amniocytes or chorionic villus samples have all been used as screening methods [8]. A typical starting dose of hydrocortisone is 20 to $30 \mathrm{mg} / \mathrm{m}^{2} /$ day divided thrice daily (ie, $2.5 \mathrm{mg}$ three times a day), fludrocortisone $100 \mathrm{mcg}$ twice daily, and one gram or $4 \mathrm{mEq} / \mathrm{kg} / \mathrm{day}$ of sodium chloride divided in several feedings. Higher doses of hydrocortisone (ie, $50 \mathrm{mg} / \mathrm{m}^{2} /$ day) may be used for initial reduction of markedly elevated adrenal hormones, but it is important to very rapidly reduce the dose when target hormone levels are achieved. Once results are available, medication dose titration should be performed with repeat blood sampling and blood pressure monitoring at least monthly [2].

The clinical course in patients with classic $\mathrm{CAH}$ and 21-hydroxylase defect depends on early diagnosis of the disease. Positive findings of screening for $\mathrm{CAH}$ need to be verified quickly by clinical and endocrinological evidence. The patients identified should be treated by pediatricians within the scope of medical family care in close cooperation with pediatric endocrinologists.

\section{Conclusion}

The goal of the present article is to enlighten others about usefulness of newborn Screening and to keep $\mathrm{CAH}$ as a differential in any neonate who presents with shock and unresponsive sepsis.

Funding: Nil, Conflict of interest: None initiated, Perission from IRB: Yes

\section{References}

1. Merke DP, Bornstein SR. Congenital adrenal hyperplasia. Lancet. 2005 Jun 18-24; 365 (9477): 2125-36.

2. Speiser PW, Azziz R, Baskin LS, Ghizzoni L, Hensle TW, Merke DP, Meyer-Bahlburg HF, Miller WL, Montori VM, Oberfield SE, Ritzen M, White PC; Endocrine Society. Congenital adrenal hyperplasia due to steroid 21-hydroxylase deficiency: an Endocrine Society clinical practice guideline. J Clin Endocrinol Metab. 2010 Sep; 95(9):4133-60. doi: 10.1210/jc. 2009-2631

3. Witchel SF, Nayak S, Suda-Hartman M, Lee PA. Newborn screening for 21-hydroxylase deficiency: results of CYP21 molecular genetic analysis. J Pediatr. 1997 Aug;131(2):328-31.
4. Al-Alwan I, Navarro O, Daneman D, Daneman A. Clinical utility of adrenal ultrasonography in the diagnosis of congenital adrenal hyperplasia. J Pediatr. 1999 Jul;135(1):71-5.

5. Gonzalez RR, Mäentausta O, Solyom J, Vihko R. Direct solid-phase time-resolved fluoroimmunoassay of 17 alpha-hydroxyprogesterone in serum and dried blood spots on filter paper. Clin Chem 1990; 36:1667.

6. Minutti CZ, Lacey JM, Magera MJ, et al. Steroid profiling by tandem mass spectrometry improves the positive predictive value of newborn screening for congenital adrenal hyperplasia. J Clin Endocrinol Metab 2004; 89:3687.

7. Nordenström A, Thilén A, Hagenfeldt L, Larsson A, Wedell A. Genotyping is a valuable diagnostic complement to neonatal screening for congenital adrenal hyperplasia due to steroid 21-hydroxylase deficiency. J Clin Endocrinol Metab. 1999 May;84 (5): 1505-9.

8. Mornet E, Boue J, Raux-Demay M, et al. First trimester prenatal diagnosis of 21-hydroxylase deficiency by linkage analysis to HLA-DNA probes and by 17-hydroxyprogesterone determination. Hum Genet 1986; $73: 358$.

\section{How to cite this article?}

Balaji MD, Madhava Kamath K, B. Aditya Kumar. Congenital adrenal hyperplasia in a male neonate presenting as unresponsive sepsis. J PediatrRes. 2017; 4(02):182-184.doi:10.17511/ijpr.2017.i02.16. 